\title{
Comparison of morbidity between axillary lymph node dissection and sentinel node biopsy
}

\author{
M. P. Schijven*, A. J. J. M. Vingerhoets†, H. J. T. Rutten*, \\ G. A. P. Nieuwenhuijzen*, R. M. H. Roumen $\ddagger$, M. E. van Bussel $\dagger$ \\ and A. C. Voogd§
}

\begin{abstract}
*Department of Surgery, Catharina Hospital Eindhoven, The Netherlands, †Section of Clinical Health Psychology, Tilburg University, Tilburg, The Netherlands, ‡Department of Surgery, St Joseph Hospital, Veldhoven, The Netherlands and §Comprehensive Cancer Centre South, Eindhoven Cancer Registry, Eindhoven, The Netherlands
\end{abstract}

\begin{abstract}
Aims: The use of axillary lymph node dissection (ALND) in women with breast cancer is associated with considerable morbidity. Sentinel node biopsy (SNB) removes the lymph node in the axillary basin indicative for receiving first lymphatic drainage from the breast. This study compares the nature and severity of physical morbidity among breast cancer patients who underwent primary surgery for breast cancer combined with either ALND or SNB. Also, it assesses influence of subsequent radiotherapy on morbidity.

Method: Two hundred and thirteen ALND patients were compared with 180 SNB patients retrospectively. Morbidity was measured using a disease-specific quality-of-life questionnaire.

Results: Patients' demographic characteristics were alike. The axillary procedure is the strongest and most consistent factor in explaining differences in a variety of self-reported complaints. Patients having had SNB have a 3.2-fold lower risk of experiencing pain, a 5-fold lower risk of lymph oedema, a 7.7-fold lower risk of numbness, a 3.7-fold lower risk of tingling sensations, a 7.I-fold lower risk of loss of strength in arm/hand, a 3.6-fold lower risk of loss of active motion range of the arm and a 2.9-fold lower risk of impaired use of the arm. Axillary radiation therapy adds to complaints next to the axillary surgical procedure by increasing the risk of lymph oedema 2.4-fold and enhancing the risk of impaired use of the arm by 2.6-fold. Axillary radiation therapy does not explain lymph oedema by itself.
\end{abstract}

Conclusion: SNB is associated with less morbidity compared to ALND in patients with primary breast cancer.

(c) 2002 Elsevier Science Ltd. All rights reserved.

Key words: breast cancer; axillary lymph node dissection; sentinel node biopsy; lymph oedema; quality of life.

\section{INTRODUCTION}

For decades, axillary lymph node dissection (ALND) has been the standard procedure in surgical treatment of patients with breast cancer. In the past few years, screening mammography and increased public awareness has led to a decrease in detected tumour size. As a result, fewer women have axillary lymph node involvement. It is thought that over ninety per cent of woman having breast tumours smaller than $\mathrm{I} \mathrm{cm}$ have no involvement of the axillary lymph nodes. ${ }^{1-8}$ Next to tumour size, the extent of axillary involvement is

Correspondence to: M. P. Schijven, M.D., Department of Surgery, Catharina Hospital Eindhoven, Michelangelolaan 2, P.O. Box 1350, 5602 ZA Eindhoven, The Netherlands. Tel: +3I 40 2397I50; Fax: +3l 40 2443370; E-mail: mschijv@zonnet.nl considered to be the most important prognostic indicator for breast cancer survival. ${ }^{8}$ Gold-standard in determining actual axillary lymph node involvement in breast cancer patients is by means of performing ALND. Of value in obtaining regional control of metastasized breast cancer in the axilla, the importance of ALND is shifting from being an integral part of breast cancer treatment towards being a critical element for staging purposes and adjuvant treatment determination. Routine performance of ALND, and its alleged impact on disease-free or overall survival is under discussion. ${ }^{9-13}$ ALND comes at cost to the patient. It induces postoperative morbidity such as lymph oedema, pain, numbness, loss of strength and impaired range of motion of the involved arm..$^{11,14-17}$ Next to the extent of surgery in the axilla, the number of removed lymph nodes, the tumour burden of the nodes and 
postoperative axillary radiation therapy have been shown to be related to morbidity. ${ }^{16}$ Limiting the extent of surgery to the axilla is likely to diminish morbidity. In this respect, sentinel node biopsy (SNB) has become the object of study in breast cancer patients. The technique has first been described by Cabanas in patients with penile carcinoma. ${ }^{18}$ SNB has been extensively validated in patients with stage I melanoma by Morton et al., and the concept is currently extended to breast cancer populations. ${ }^{19}$ Preliminary studies have shown that SNB in breast cancer populations, compared to standard ALND, has a sensitivity varying from $85 \%$ to $98 \%$. $^{12,20-27}$

In experienced hands, SNB may decrease axillary morbidity preserving optimal conditions for detecting axillary metastasis. ALND could then be reserved for those patients proven to have axillary lymph node metastasis by SNB.

Physical problems resulting from ALND are well documented. ', 2,17 Few studies have compared physical morbidity of ALDN with SNB reflecting the impact of both techniques on the patient's quality-of-life. ${ }^{16}$ The present study focuses on frequency and severity of selfreported physical complaints and problems in daily life among breast cancer patients having had different surgical approaches to the axilla. The aim of this study is to assess the influence of the axillary procedure and subsequent adjuvant treatment on post-operative morbidity in breast cancer patients.

\section{MATERIALS AND METHODS}

\section{Patients}

From December 1998 until May 1999, specialists approached breast cancer patients having had ALDN within the last three years. Patients were considered eligible if they underwent ALND as part of surgical treatment for primary breast cancer, were at least three months post-treatment (including radiation and/or adjuvant hormonal or chemotherapy) and without signs of active disease. In order to prevent selection bias, specialists were requested to approach ALND patients consecutively during scheduled follow-up appointments irrespective of the presence of complaints after surgery. SNB patients were considered eligible for our study if they underwent SNB as part of surgical treatment for primary breast cancer within the last 3 years, were at least three months post-treatment and without signs of active disease. SNB patients were consecutively selected from hospital patient files.

\section{Technique}

Patients underwent either lumpectomy or mastectomy, combined with ALND or SNB. ALND was performed according to established guidelines. Mean number of lymph nodes removed was 10. The SNB procedure was facilitated by administration of 100 Megabec querel (Mbq) in $0.5 \mathrm{~mL}$ of ${ }^{99 \mathrm{~m}} \mathrm{Tc}$-colloidal-labelled albumin (Nanocoll), peri-tumoural, the day prior to surgery. Static imaging of the axilla using a gamma-camera was done at the Department of Nuclear Medicine immediately before surgery. Under general anaesthesia, the patient was injected around the areola with Patent Blue $V$ dye for optimal visualization of lymphatics and lymph nodes ( $2.5 \%$ solution, Laboratoire Guerbet, Aulnay-sous-Bois, France, injected peri-areolar subdermally). The sentinel node was harvested through a small, $2-3 \mathrm{~cm}$ wide skincrease incision guided by skin surface markings indicative for the visualized sentinel nodes on static films, and by combined visual/hand-held gamma probe localization.

ALND patients started physical therapy from day one post-operatively until optimal motion range was achieved. Most patients were given a drain during surgery in the axillary region. The drain was usually removed when production was below $40 \mathrm{cc} / 24 \mathrm{~h}$. At discharge, patients were instructed by a trained nurse how to resume optimal use of the arm and how to exercise at home. Patients were seen on outpatient basis according to protocoled follow-up schedule, starting one week after discharge. SNB patients were not given routine wound drains. SNB patients were usually discharged one to two days post-operatively. No routine hospital physical therapy was started in the SNB group.

Radiation therapy to the axilla and/or supraclavicular region was recommended for patients with inadequate ALND, extra-capsular malignant growth at lymph node involvement or nodal involvement in the apex of the axilla. In the SNB group, ALND was performed in patients with a positive sentinel node on H\&E staining, and radiation therapy recommended according to the pathological outcome of ALND. Irradiation of the axilla and the supraclavicular region was recommended for patients with inadequate ALND, extra-capsular extension of tumour growth or nodal involvement in the apex of the axilla. Patients received post-operative adjuvant hormone or chemotherapy depending on their individual characteristics combined with the results of pathology including breast tissue and axillary node histology, mitosis index of the tumour and its oestrogen/progesterone receptor status.

\section{Questionnaire}

Eligible patients received a treatment-specific quality-oflife questionnaire. This questionnaire was developed and validated by the department of Clinical Health Psychology of Tilburg University, The Netherlands. The questionnaire was pre-tested and construct- as well as content-validated in pilot study. ${ }^{28}$ Additional data, such as pTNM classification and post-operative treatment regimen were retrieved from hospital patient files. 


\section{Statistics}

Fisher's exact test, Student's t-test and the Kolmogorov-Smirnov test were used to analyse variables in frequency tables, depending on scale of measurement. Multivariate logistic regression analysis was applied to assess association between patient and treatment characteristics and risk on complaints. For this purpose, the original four-point Likert scale was dichotomized. Response categories 2 and 3 were recoded as 'complaint present', categories 0 and I as 'complaint absent'. Odds Ratios (OR) and 90\% confidence intervals - as a direction of diminishment of the complaint in the SNB group was to be expected - were computed. Variables included in the regression model were: axillary procedure (SNB vs ALND); cancer stage (stage 2 vs stage I); time since axillary surgery ( $>2$ years ago vs $\leq 2$ years ago); age groups $I$ and $2(<50$ years vs $65+$ and $50-64$ years vs $65+$ ); treatment (lumpectomy vs mastectomy); radiation therapy one and two (not irradiated vs irradiated on breast/chest wall, but not on axilla or supraclavivular; and irradiated on breast/chest wall, but not on axilla or supraclavicular); chemotherapy (yes vs no); hormonal therapy (yes vs no); axillary surgery ipsilateral to handedness (yes vs no). Only variables with $P$-values less or equal to 0.05 (alpha) were considered to be of statistical significance, and kept in regression analysis using the stepwise-backward selection principle, selecting variables with a significance level of $P<0.10$ into the model.

This study was set up and coordinated by the Section of Clinical Health Psychology of Tilburg University and the Comprehensive Cancer Centre South in Eindhoven, The Netherlands. Eight departments of surgery, one department of radiotherapy and one department of internal medicine of eight community centre hospitals in the South-East Netherlands participated in the study. Approval was obtained from the Medical Ethical Committees of participating hospitals and of the Comprehensive Cancer Centre South. The departments of surgery of the Catharina Hospital Eindhoven and the St Joseph Hospital Veldhoven, being the first ones in the region performing sentinel node biopsy, were selected for inclusion of SNB patients. Both centres evaluated reliability of their clinical application of the SNB procedure. ${ }^{29,30}$

\section{RESULTS}

Of the 465 questionnaires sent to ALND patients, 400 (86\%) were returned. In addition, of the 248 questionnaires sent to SNB patients, 198 (79\%) were returned. Only patients with updated and comprehensive patient records, who filled in the questionnaire completely, were included. This resulted in a reduction of group size for the ALND patients to 213 patients and a group size for SNB patients of 180 patients.

\section{Patient characteristics}

Variables representing patients' demographics and treatment characteristics are presented in Table I. Groups do not differ in age, level of education, civil status, number of children, professional activity and health care insurance. In contrast, primary surgery differs among groups; patients who underwent SNB received breast-conserving primary surgery more often. Considering the pTNM-classification, patient groups do not to differ significantly in tumour size, although there is skewness-to-the-side towards a more favourable tumour size in the SNB group. Table 2 illustrates relationships between tumour stage, primary procedure and axillary surgery. SNB patients having a mastectomy mostly did so because they were diagnosed with ductal carcinoma in situ (Tis), whereas ALND patients having a mastectomy did so because of larger tumour size. Both groups have a similar percentage of PTI patients, in the mastectomy population (approx. 50\%) as well as in the lumpectomy population (approx. 75\%). Axillary nodal state and tumour size, reflected in the stage-classification of patients, are unequally divided between groups. This can partly be explained by the larger proportion of Tis patients in the SNB group, and partly by less involvement of the axillary nodes in the SNB group.

It is important to realize that the staging of the patient actually is a pathologically based figure, calculated after the surgical procedure has been performed. Therefore, staging as a parameter is invalid in its proposed influence on morbidity itself. However, it is indicative of the selection of individual-adjuvant therapy. Radiotherapy differs among groups. Radiotherapy is more frequently applied in the SNB group, but relatively more patients in the ALND group received radiotherapy to the axillary region. ALND patients received chemotherapy more often but hormonal therapy less often. The majority of patients in the SNB group underwent surgery (less than) one year from questioning; the majority of patients in the ALND group underwent surgery $2-3$ years from participation in the present study.

\section{Frequency and severity of arm problems and arm-related complaints: SNB group versus ALND group}

The frequency and severity of arm-related complaints are presented in Tables 3 and 4. Table 3 represents the entire set of complaints patients where asked for in the Physical Domain section of the questionnaire. The fourpoint Likert scale has been dichotomized to complaint 'absent' or 'present'. Selection of complaints resulted according to authors' opinion on importance, as well as their results when tested for significance (Table 3). Frequently (i.e. $>20 \%$ ) reported physical complaints in the ALND group were: loss of strength in arm/hand 
Table I Comparison of demographic-, treatment- and disease-specific characteristics between ALND patients and SNB patients

\begin{tabular}{|c|c|c|c|}
\hline Patient and treatment characteristics & $\begin{array}{c}\text { ALND (\%) } \\
(n=213)\end{array}$ & $\begin{array}{l}\text { SNB (\%) } \\
(n=180)\end{array}$ & $P$-value \\
\hline \multicolumn{4}{|l|}{ Age when having surgery (years) ${ }^{3}$} \\
\hline$<50$ & 27.7 & 20.5 & \\
\hline $50-65$ & 54.4 & 46.5 & \\
\hline$\geq 65$ & 17.8 & 33.0 & 0.17 \\
\hline \multicolumn{4}{|l|}{ Time since axillary surgery (years) ${ }^{2}$} \\
\hline$<1$ & 0.0 & 9.1 & \\
\hline I & 38.0 & 50.0 & \\
\hline 2 & 36.2 & 36.9 & \\
\hline 3 & 25.8 & 4.0 & $0.00 *$ \\
\hline \multicolumn{4}{|l|}{ Primary surgery ${ }^{I(\text { see also Table la) }}$} \\
\hline Lumpectomy & 66.2 & 88.3 & \\
\hline Mastectomy & 33.8 & 11.7 & $0.00 *$ \\
\hline \multicolumn{4}{|l|}{ Axillary surgery on ipsilateral side as primary surgery ${ }^{2}$} \\
\hline No & 44.6 & 48.0 & \\
\hline Yes & 54.9 & 50.3 & \\
\hline Ambidextrous & 0.5 & 1.7 & $0.75^{*}$ \\
\hline \multicolumn{4}{|l|}{ pTNM-classification ${ }^{2}$} \\
\hline $\mathrm{pT}$ is & 0.5 & 6.7 & \\
\hline PTI (tumour size $\leq 2 \mathrm{~cm}$ ) & 67.1 & 71.1 & \\
\hline PT2 (tumour size $>2 \mathrm{~cm}$ and $\leq 5 \mathrm{~cm}$ ) & 27.2 & 21.1 & \\
\hline PT3 (tumour size $>5 \mathrm{~cm}$ ) & 1.9 & 0.6 & \\
\hline PT4 (tumour invading skin or thorax, regardless of size) & 3.3 & 0.6 & 0.27 \\
\hline pN0 (no positive axillary lymph node/s) & 58.8 & 78.9 & \\
\hline $\begin{array}{l}\mathrm{pN} \text { or } \mathrm{pN} 2 \text { (metastasis in movable ipsilateral node/s; } \\
\text { metastasis in fixed ipsilateral node/s) }\end{array}$ & 41.2 & 21.1 & $0.00 *$ \\
\hline \multicolumn{4}{|l|}{ Stage $^{2}$} \\
\hline Stage 0 (is) & 0.5 & 6.7 & \\
\hline Stage I & 46.9 & 58.3 & \\
\hline Stage 2 & 46.5 & 33.9 & \\
\hline Stage 3 & 6.1 & 1.1 & \\
\hline Stage 4 & 0 & 0 & $0.01 *$ \\
\hline \multicolumn{4}{|l|}{ Radiotherapy $^{2}$} \\
\hline No & 28.4 & 17.2 & \\
\hline Yes, on axilla & 13.9 & 8.3 & \\
\hline Yes, not on axilla & 57.7 & 74.4 & $0.01 *$ \\
\hline \multicolumn{4}{|l|}{ Chemotherapy ${ }^{\prime}$} \\
\hline No & 81.2 & 89.4 & \\
\hline Yes & 18.8 & 10.6 & $0.02 *$ \\
\hline \multicolumn{4}{|l|}{ Hormonal therapy' } \\
\hline No & 76.1 & 64.4 & \\
\hline Yes & 23.9 & 35.6 & $0.01 *$ \\
\hline \multicolumn{4}{|l|}{ Civil status ${ }^{\prime}$} \\
\hline Single/divorced/widow & 25.9 & 27.0 & \\
\hline Married/living together & 74.1 & 73.0 & 0.82 \\
\hline \multicolumn{4}{|l|}{ Children' } \\
\hline No & 8 & 15.2 & \\
\hline Yes & 92 & 84.8 & $0.04 *$ \\
\hline \multicolumn{4}{|l|}{ Level of Education ${ }^{2}$} \\
\hline Primary & 27.5 & 27.3 & \\
\hline Secondary/Professional & 58.3 & 55.2 & \\
\hline Higher (e.g. college or university) & 14.2 & 17.4 & 1.0 \\
\hline \multicolumn{4}{|l|}{ Professionally active (other than full-time housewife) ${ }^{\prime}$} \\
\hline No & 59.1 & 62.2 & \\
\hline Yes & 40.9 & 37.8 & 0.62 \\
\hline
\end{tabular}




\begin{tabular}{|c|c|c|c|}
\hline Patient and treatment characteristics & $\begin{array}{c}\text { ALND (\%) } \\
(n=213)\end{array}$ & $\begin{array}{l}\text { SNB }(\%) \\
(n=180)\end{array}$ & $P$-value \\
\hline \multicolumn{4}{|l|}{ Professional inactivity related to surgery ${ }^{2}$} \\
\hline Inactive before surgery & 47.7 & 48.3 & \\
\hline Inactive since surgery & 8.7 & 9.2 & \\
\hline active & 43.6 & 42.5 & 1.0 \\
\hline \multicolumn{4}{|l|}{ Health care insurance } \\
\hline Public & 64.8 & 69.3 & \\
\hline Private & 35.2 & 30.7 & 0.39 \\
\hline
\end{tabular}

Table 2 Relationship between tumour stage, primary procedure and axillary surgery

\begin{tabular}{|c|c|c|c|c|c|c|c|c|}
\hline \multirow[t]{2}{*}{ Stage } & \multicolumn{2}{|c|}{ Mastectomy } & \multicolumn{2}{|c|}{ Mastectomy } & \multicolumn{2}{|c|}{ Lumpectomy } & \multicolumn{2}{|c|}{ Lumpectomy } \\
\hline & SNB (\%) & $n$ & ALND (\%) & $n$ & SNB (\%) & $n$ & ALND (\%) & $n$ \\
\hline Tis & 23.8 & 5 & 1.4 & I & 4.4 & 7 & & \\
\hline PTI & 47.6 & 10 & 51.4 & 37 & 74.2 & 118 & 75.2 & 106 \\
\hline PT2 & 23.8 & 5 & 34.7 & 25 & 20.8 & 33 & 23.4 & 33 \\
\hline PT3 & 4.8 & I & 4.2 & 3 & & & 0.7 & I \\
\hline PT4 & & & 8.3 & 6 & 0.6 & I & 0.7 & I \\
\hline
\end{tabular}

Table 3 Comparison of the proportion of patients with complaints after ALND/SNB

\begin{tabular}{|c|c|c|c|}
\hline Morbidity after axillary surgery & $\begin{array}{c}\text { ALND }(n=213) \\
\text { complaint present \% }\end{array}$ & $\begin{array}{c}\text { SNB }(n=180) \\
\text { complaint present } \%\end{array}$ & $P$-value* \\
\hline Painful arm/shoulder & 23.0 & 7.8 & 0.00 \\
\hline Lymph edema & 7.1 & 1.1 & 0.00 \\
\hline Numbness of arm/hand & 24.4 & 3.9 & 0.00 \\
\hline Tingling sensations in arm/hand & 14.6 & 3.9 & 0.00 \\
\hline Loss of strength in arm/hand & 26.3 & 3.9 & 0.00 \\
\hline Cannot use arm to former extent & 21.2 & 7.7 & 0.00 \\
\hline Treated by physiotherapist ${ }^{\prime}$ & 37.6 & 11.2 & 0.00 \\
\hline Currently being treated by physiotherapist ${ }^{\prime}$ & 18.8 & 10.3 & 0.02 \\
\hline $\begin{array}{l}\text { Loss of full active motion } \\
\text { range of arm }\end{array}$ & 18.3 & 6.0 & 0.02 \\
\hline $\begin{array}{l}\text { Use of other hand due to } \\
\text { discomfort of hand on affected side }\end{array}$ & 20.6 & 4.5 & 0.00 \\
\hline Experience of difficulties at domestic tasks & 15 & 7.8 & 0.00 \\
\hline
\end{tabular}

All tests, unless stated otherwise, performed trough: two-sample Kolmogorov-Smirnov test, 2-tailed.

' Fishers exact test, 2-tailed.

* Statistically significant at $\alpha: 0.05$.

(26.3\%); numbness of arm/hand (24.4\%); painful arm/ shoulder $(23 \%)$; inability to use arm to former extent (21.1\%); and use of other hand due to discomfort of hand on affected side (20.6\%). In the SNB group, all complaints are reported less frequently. Most frequently reported complaints in the SNB group are a painful arm/shoulder (7.8\%) and the experience of difficulties performing domestic tasks (7.8\%). A variable often mentioned in literature to be debilitating after ALND is lymph oedema. Virtually non-existent in the SNB group ( $1.1 \%$ ), in the ALND group, I:I5 patients is reporting severe oedema. 
Table 4 Multivariate logistic regression analysis for seleted physical complaints

\begin{tabular}{|c|c|c|c|c|}
\hline Item & $\mathrm{OR}^{\prime}$ & $\mathrm{I}_{\mathrm{OOR}}{ }^{2}$ & $90 \% \mathrm{Cl}$ & $P$-value \\
\hline \multicolumn{5}{|l|}{ Painful arm/shoulder } \\
\hline SNB vs ALND & 0.31 & 3.23 & $(0.18-0.52)^{*}$ & 0.03 \\
\hline \multicolumn{5}{|l|}{ Lymph edema } \\
\hline SNB vs ALND & 0.2 & 5.0 & $(0.12-0.32)^{*}$ & 0.00 \\
\hline $\begin{array}{l}\text { Axillary/supraclavicular irradiation vs irradiation } \\
\text { on breast or chestwall, but not on axilla/supraclavicular region }\end{array}$ & 2.44 & 0.41 & $(1.31-4.52)^{*}$ & 0.02 \\
\hline Time since axillary surgery $>2$ years ago vs $\leq 2$ years ago & 2.19 & 0.46 & $(1.41-3.40)^{*}$ & 0.00 \\
\hline $\begin{array}{l}\text { No irradiation vs irradiation on breast or chestwall, but not } \\
\text { on axilla/supraclavicular region }\end{array}$ & 0.90 & 1.10 & $(0.54-1.48)$ & 0.72 \\
\hline \multicolumn{5}{|l|}{ Numbness of arm/hand } \\
\hline SNB vs ALND & 0.13 & 7.69 & $(0.06-0.26)^{*}$ & 0.00 \\
\hline Age $<50$ years vs age $65+$ & 3.39 & 0.29 & $(1.55-7.45)^{*}$ & 0.01 \\
\hline Age $50-64$ years vs age $65+$ & 1.34 & 0.74 & $(0.70-2.59)$ & 0.46 \\
\hline Chemotherapy vs no chemotherapy & 0.47 & 2.12 & $(0.22-1.00)$ & 0.10 \\
\hline \multicolumn{5}{|l|}{ Tingling sensations in arm/hand } \\
\hline SNB vs ALND & 0.27 & 3.70 & $(0.13-0.54)^{*}$ & 0.00 \\
\hline \multicolumn{5}{|l|}{ Loss of strength in arm/hand } \\
\hline SNB vs ALND & 0.14 & 7.14 & $(0.07-0.28)^{*}$ & 0.00 \\
\hline Lumpectomy vs mastectomy & 0.55 & 1.82 & $(0.33-0.92)^{*}$ & 0.05 \\
\hline \multicolumn{5}{|l|}{ Loss of full active motion range of arm } \\
\hline SNB vs ALND & 0.28 & 3.57 & $(0.15-0.53)^{*}$ & 0.01 \\
\hline Stage 2 or 3 vs stage in situ or I & 2.03 & 0.49 & $(1.18-3.50)^{*}$ & 0.03 \\
\hline \multicolumn{5}{|l|}{ Cannot use arm to former extent } \\
\hline SNB vs ALND & 0.34 & 2.94 & $(0.20-0.58)^{*}$ & 0.00 \\
\hline $\begin{array}{l}\text { Axillary/supraclavicular irradiation vs irradiation on } \\
\text { breast or chestwall, but not on supraclavicular/ } \\
\text { supraclavicular region }\end{array}$ & 2.64 & 0.37 & $(1.4 I-4.96)^{*}$ & 0.01 \\
\hline $\begin{array}{l}\text { No irradiation vs irradiation on breast or chestwall, } \\
\text { but not on axilla/supraclavicular region }\end{array}$ & 0.76 & 1.32 & $(0.4 I-1.43)$ & 0.48 \\
\hline \multicolumn{5}{|l|}{ Treated by physiotherapist } \\
\hline SNB vs ALND & 0.24 & 4.17 & $(0.15-0.39)^{*}$ & 0.00 \\
\hline Lumpectomy vs mastectomy & 0.5 & 2.00 & $(0.28-0.88)^{*}$ & 0.04 \\
\hline $\begin{array}{l}\text { No irradiation vs irradiation on breast or chestwall, but not on } \\
\text { axilla/supraclavicular region }\end{array}$ & 0.51 & 1.96 & $(0.27-0.95)^{*}$ & 0.07 \\
\hline $\begin{array}{l}\text { Axillary/supraclavicular irradiation vs irradiation on breast } \\
\text { or chestwall, but not on supraclavicular/supraclavicular region }\end{array}$ & 1.69 & 0.59 & $(0.90-3.15)$ & 0.17 \\
\hline \multicolumn{5}{|l|}{ Currently being treated by physiotherapist } \\
\hline SNB vs ALND & 0.45 & 2.22 & $(0.27-0.78) *$ & 0.02 \\
\hline $\begin{array}{l}\text { No irradiation vs irradiation on breast or chestwall, but not on } \\
\text { axilla/supraclavicular region }\end{array}$ & 0.54 & 1.85 & $(0.27-1.07)$ & 0.14 \\
\hline $\begin{array}{l}\text { Axillary/supraclavicular irradiation vs irradiation on breast or } \\
\text { chestwall, but not on supraclavicular/supraclavicular region }\end{array}$ & 2.02 & 0.49 & $(1.06-3.83)$ & 0.07 \\
\hline Hormonal therapy vs no hormonal therapy & 1.75 & 0.57 & $(1.04-2.95)$ & 0.08 \\
\hline \multicolumn{5}{|l|}{$\begin{array}{l}\text { Use of other hand due to discomfort of hand } \\
\text { on affected side }\end{array}$} \\
\hline SNB vs ALND & 0.25 & 4.00 & $(0.13-0.49)^{*}$ & 0.00 \\
\hline Lumpectomy vs mastectomy & 0.36 & 2.78 & $(0.18-0.70) *$ & 0.01 \\
\hline $\begin{array}{l}\text { No irradiation vs irradiation on breast or chestwall, but not on } \\
\text { axilla/supraclavicular region }\end{array}$ & 0.65 & 1.54 & $(0.30-1.39)$ & 0.35 \\
\hline $\begin{array}{l}\text { Axillary/supraclavicular irradiation vs irradiation on breast or } \\
\text { chestwall, but not on supraclavicular/supraclavicular region }\end{array}$ & 1.97 & 0.51 & $(0.94-4.13)$ & 0.13 \\
\hline
\end{tabular}




\begin{tabular}{|c|c|c|c|c|}
\hline Item & $\mathrm{OR}^{\prime}$ & $\mathrm{I}_{\mathrm{O}} \mathrm{OR}{ }^{2}$ & $90 \% \mathrm{Cl}$ & $P$-value \\
\hline \multicolumn{5}{|l|}{ Experience of difficulties at domestic tasks } \\
\hline SNB vs ALND & 0.58 & 1.72 & $(0.33-1.00)$ & 0.10 \\
\hline $\begin{array}{l}\text { Axillary surgery on contralateral side as primary surgery vs } \\
\text { axillary surgery on ipsilateral side as primary surgery }\end{array}$ & 0.58 & 1.72 & $(0.34-0.98)^{*}$ & 0.09 \\
\hline
\end{tabular}

Table 5 Relationship between axillary surgery, radiation therapy and lymph edema

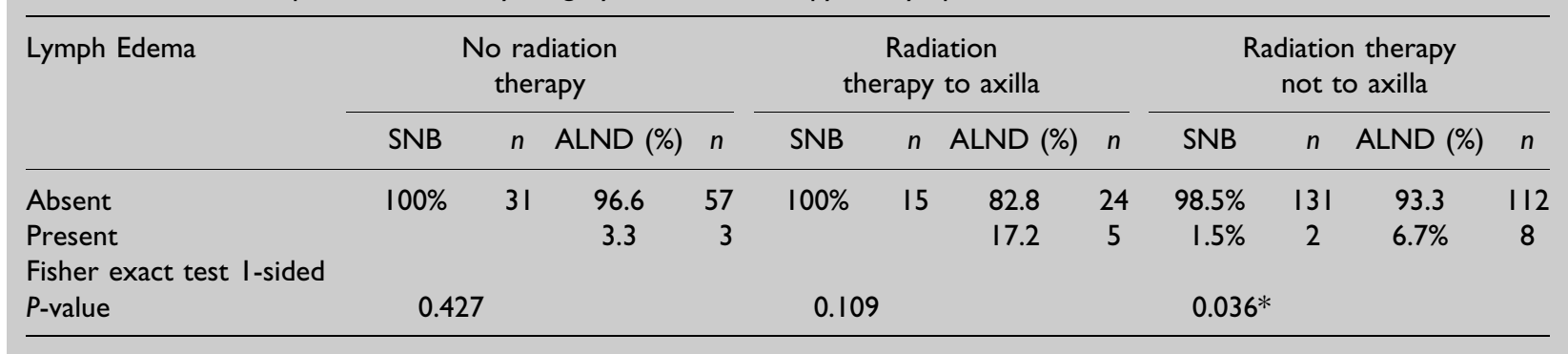

Over one in three ALND patients have had physiotherapy, compared to I to 9 patients in the SNB group. Almost 19\% of ALND patients are still being treated by the physiotherapist.

\section{RISK FACTORS}

Table 4 specifies the odds ratios (ORs), resulting from multivariable logistic regression analysis on the selected set of complaints. SNB patients have a 3.2-fold lower risk of experiencing a painful arm or shoulder after surgery than ALND patients. SNB patients are five times less likely to experience lymph oedema. Axillary radiation and elapsed time since surgery are also important variables in the model for estimating the risk on lymph oedema. Table 5 illustrates relation between radiation therapy, axillary surgical procedure and presence of lymph oedema. In the SNB group, lymph oedema is absent even when patients are irradiated on the axilla. In the ALND group, there is a difference of $14 \%$ in reported lymph oedema between patient without and patients with radiation therapy to the axilla. There is a difference of $10.5 \%$ between patients with radiation therapy to the breast or chest wall but not to the axilla and patients with radiation therapy to the axilla. Only two patients in the SNB group report often to have lymph oedema. These two patients have both had a lumpectomy, and were both node-negative, but have been irradiated on the breast. Radiation therapy seems not to explain the presence of lymph oedema in patients having had none (FET 0.43) and for patients having had radiation therapy to the axilla (FET $0.1 \mathrm{I}$ ). The axillary procedure contributes significantly to experiencing numbness of the affected arm/hand. In addition, the age of the patient is of importance, indicating that patients younger than 50 years have a 3.4-fold higher risk on reporting numbness compared to patients over 65 years of age. For the questions concerning tingling sensations (OR 3.7), loss of full active motion range (OR 3.6) and use of arm to former extent (OR 2.9), SNB patients have significant lower risk of complaints. The pathologic stage of the patients is, in retrospect, of importance for indicating loss of full active motion range (higher stage indicating a 2.I-fold higher risk). Patients who underwent radiation therapy to the axilla are 2.4 times more at risk for experiencing lymph oedema and 2.6 times more prone to experiencing impaired use of the arm. Axillary radiation therapy does not contribute significantly for being, ever, under treatment of a physiotherapist; neither is axillary radiation therapy explaining the use of the other hand due to discomfort. Considering loss of strength and use of the other hand due to discomfort on the affected side, primary procedure and axillary procedure are both of influence, favouring less invasive surgery. SNB patients have a 7.Ifold lower risk of loss of strength, and a 4-fold lower risk of use of the other hand due to discomfort.

SNB patients have a 4-fold, and in the lumpectomy patients have a 2 -fold lower chance of ever being treated 
by a physiotherapist compared to ALND patients and mastectomy patients, respectively. Having had no radiation therapy at all seems to be reducing the risk for needing a physiotherapist by 2 -fold.

\section{DISCUSSION}

The purpose of this study was to compare nature and severity of morbidity among breast cancer patients having undergone traditional axillary lymph node dissection (ALND) vs breast cancer patients having undergone sentinel node biopsy (SNB). Our findings indicate that self-reported morbidity after SNB is significantly reduced in comparison to post-ALND morbidity.

Lymph oedema is a common and troublesome problem that can develop following breast cancer treatment. It is believed to cause a significant diminution in health-related quality of life for breast cancer patients. ${ }^{31}$ Lymph oedema can cause limitations in range of motion, pain, weakness or stiffness in the affected extremity. ${ }^{32}$ In literature, a broad range of incidence for post-operative lymph oedema, varying widely from $6 \%$ to $56 \%$ in ALND patients, depending on definition, method of measurement, extent of axillary surgery, number of different surgeons, choice of adjuvant therapy and time elapsed since operation. ${ }^{17,33}$ Across treatment and time since treatment, approximately a quarter of patients are believed to develop arm oedema. ${ }^{34}$ The addition of radiotherapy to the dissected axilla is thought to be a strong contributor to lymph oedema. In one study, radiation therapy to the breast and to the breast and axillary nodes is reported to increase lymph oedema over mastectomy alone by 4-15\% and 30\%, respectively. ${ }^{35}$ Liljegren and Holmberg argue, according to their randomized controlled trial, that radiation therapy to the breast alone does not adversely affect the arm during the first three postoperative years. Only age and number of lymph nodes harvested predict oedema or subjective arm symptoms in their multivariate model. ${ }^{36}$ Borup Christensen and Lundgren found incidence of arm oedema to be significantly higher in a group with ALND and axillary radiation therapy (44\%) than in the group with axillary radiation therapy alone $(10 \%)$ or in the groups with axillary sampling, with or without radiation therapy $(0 \%){ }^{37}$ Across a number of studies, lymph oedema has been reported to occur in approximately $41 \%$ (range $2 \mid-5 I \%)$ of patients who undergo axillary radiation therapy in addition to surgery therapy as opposed to approximately 17\% (range 6-39\%) of patients treated with surgery but no radiation therapy. ${ }^{17}$ Only one, nonrandomized study has focused on the presence of lymph oedema in patients receiving ALND $(n=35)$ vs patients receiving SNB $(n=35)$. This resulted in a percentage of zero for lymph oedema among SNB patients. No patients in either ALND or SNB in this setting received axillary radiation therapy. ${ }^{16}$ In our study, two SNB patients complain of lymph oedema. As their complaints cannot be explained by radiotherapy on the axilla, the question is: can their complaints be attributed to the SNB procedure? Only one patient is consistent in reporting having lymph oedema, localized in the axilla, upper arm, elbow, lower arm and hand. The other patient indicates having lymph oedema but, asked more precisely, no location is indicated. Thus, a report-error might be most likely. SNB patients in our study have a 5fold lower chance of lymph oedema in comparison to ALND patients. Radiation therapy to the axilla increases the risk on oedema 2.4-fold. However, this association is not as strong as the surgical axillary procedure. In percentages, axillary radiation therapy in the ALND population increases the chance of lymph oedema by $13.9 \%$. In the SNB population, there is no increase in lymph oedema between patients who were not irradiated and patients who received axillary radiation therapy. SNB is, therefore, most likely to be the strongest factor in explaining low figures on lymph oedema in SNB patients compared to ALND patients.

In the ALND group, patients received chemotherapy more often but hormonal therapy less often, indicative for a larger proportion of pre-menopausal woman with axillary metastasis. This is a finding congruent with the age distribution within both groups. Remarkable in our study is the fact that as many as $8.3 \%$ of the SNB group received radiotherapy on the axilla. This might reflect different pathological work-up of the sentinel node, including multiple cross-sections, use of the polymerase chain reaction in order to detect micro-metastasis next to conventional paraffin section histology with haematoxylin-eosin staining and anticytokeratin staining. Increased work-up of the sentinel node may indeed lead to stage migration, seemingly improving prognosis in the group of breast cancer patients with small lesions. A problem much discussed is what to do with patients exhibiting micro-metastasis. Should they receive axillary radiotherapy, additional full axillary dissection, or should micro-metastasis be regarded as indicative of systemic disease? The impact of micro-metastasis in the sentinel node and its influence on long-term survival is controversial, unknown and needs to be determined in larger series, before the above questions can be answered sensibly. ${ }^{38}$ Nevertheless, it is believed that a selective policy for the management of the axilla is associated with no increase in axillary recurrence or mortality rate compared with routine axillary node clearance. Patients who are node-negative after axillary sampling can thus avoid axillary radiotherapy or axillary clearance. "

Pain, numbness, a tingling or a burning sensation in the (upper) arm region are likely to result from transsection of one or more branches of the intercostobrachial nerves during the axillary surgical procedure. Radiation therapy can contribute to these complaints by direct 
damage to the nerve or by post-irradiative inflammatory response, leading to scar tissue formation and fibrosis.

Kuehn found $23 \%$ of patients to experience pain, $73 \%$ of patients to report sensitivity problems and $14.1 \%$ to report restriction of arm following ALND without radiotherapy to the axilla.' Others found self-assessed sensitivity problems in 58-81\%, pain in $16-55 \%$, impairment of strength in $17-26 \%$ and restriction of arm motion range in 17-32\% of ALND patients. Variation resulted from various definitions and measurement techniques.' The study of Schrenk, comparing ALND to SNB, reports no pain in $94 \%$ of patients against $54 \%$ of ALND patients. In this study, there was no restriction to arm motion in the SNB group, against $17 \%$ of patients in the ALND group. Also, there was no reported loss of arm strength and no effect of operation on daily living in the SNB group. ${ }^{16}$ In our study, about $23 \%$ of ALND patients reported pain to the arm/ shoulder on the ipsilateral side of surgery, only $7.8 \%$ of SNB patients did. About $24 \%$ of ALND patients complained of numbness, only $3.9 \%$ of SNB patients did. Loss of the arm's full motion range was present in $18.3 \%$ of ALND patients, and only in $6 \%$ of SNB patients. There was loss of strength in $26.3 \%$ of ALND patients, and only in $3.9 \%$ of SNB patients. Fifteen per cent of ALND patients report experiencing difficulties performing household tasks due to their operation. Of patients who underwent SNB, only half this percentage (7.8\%) indicate experiencing difficulties in performing household tasks. In multivariate analysis, the axillary procedure is the dominant variable explaining pain, numbness, tingling sensations, loss of strength and loss of full active motion range. No significant effect of radiation therapy as a co-factor could be established. As no standardized interval-scaled scoring system was used, results should be interpreted cautiously. In general, multivariate logistic regression on variables as mentioned in Table 3 show that, for most complaints, the axillary surgical procedure is the factor of strongest influence in experiencing a variety of physical complaints in breast cancer patients, favouring less invasive surgery. Radiation therapy is increasing odds ratios on having a variety of complaints, but does not always seem to contribute to the model significantly.

\section{LIMITATIONS OF PRESENT STUDY}

Although the questionnaire was extensive and carefully formatted, patients were not questioned about what problem is considered most important to them, or most of impact on their life after their surgery for breast cancer. Furthermore, arm-circumference measurements as an objective indication of lymph oedema were not routinely performed. Parameters such as numbness of skin, pain and arm strength and mobility were not objectified by clinical measurements. In our study, almost all SNB patients were questioned within one year from intervention. Time since axillary surgery is important in estimating morbidity, as reflected in our study by a twofold higher risk on lymph oedema for patients having had axillary surgery over 2 years ago, compared to patients having more recently undergone surgery. Then again, the greater proportion of patients having had surgery over 2 years ago are ALND patients. Less-invasive techniques for staging of the axilla are most likely to decrease morbidity in breast cancer patients. One could state that this remains to be proven by a randomized controlled trial comparing SNB to ALND. Our study used a historic cohort group of ALND patients to match a less historic cohort of SNB patients. Only patients with updated and comprehensive records were selected. This poses a threat to the internal validity of the study itself, as selection bias is thus introduced. However, it is considered to be introduced randomly, and a matched and comprehensive data set was preferred above numbers of groups. Futhermore, it is unlikely that patients with small, e.g. non-palpable, tumours are willing to participate in a randomized trial, as level-2 evidence is mounting up preferring SNB for small tumour sizes. Several authors have even questioned the need for axillary surgery in older patients or in patient having a small-sized tumour. In addition, less invasive procedures enable earlier discharge, contributing to positive psychosocial effects. ${ }^{39}$

\section{CONCLUSION}

Our study shows clear differences in various aspects related to postoperative morbidity between SNB and ALND patients. Bias that is inevitably invoked due to the retrospective character and the cohort setting of the study will undoubtedly be of influence but authors feel it is highly unlikely to explain such differences in itself. Postoperative sequelae after ALND are frequently reported and may have an adverse affect on patients' quality of life. Postoperative morbidity after sentinel node procedure seems to be virtually absent. A properly implemented sentinel node technique in experienced hands is not only a safe technique for staging the axilla, in the authors' view, mandatory at least to consider as technique-of-choice in patients having small-sized breast carcinoma. Patients with a positive sentinel node will, however, still need to undergo further axillary surgery either by ALND with or without radiotherapy or, under study, by radiotherapy alone. Hence, these patients will remain at risk for the physical side-effect. Nevertheless, a substantial part of the patients with small-sized breast tumours will profit from SNB, since chances on a positive sentinel node are low.

The results of the present study firmly support the need to offer SNB to eligible breast cancer patients. 
Patients with small-sized tumours and a clinically negative axilla are most likely the ones to be optimal candidates for SNB.

\section{REFERENCES}

I. Kuehn $\mathrm{T}$ et al. Long-term morbidity following axillary dissection in breast cancer patients - clinical assessment, significance for life qualitiy and the impact of demographic, oncologic and therapeutic factors. Breast Cancer Res Treat 2000; 64: 275-86.

2. Duff $M$ et al. Prospective evaluation of the morbidity of axillary clearance for breast cancer. Br J Surg 200I; 88: II4-7.

3. Carter CL, Allen C, Hanson DE. Relation of tumor size, lymph node status and survival in 24740 breast cancer cases. Cancer 1989; 63: 181-7.

4. Fisher $B$ et al. relation of number of positive axillary nodes to the prognosis of patients with primary breast cancer. Cancer 1983; 52 I55|-7.

5. Dees EC et al. Does information from axillary dissection change treatment in clinically node-negative patients with breast cancer? Ann Surg 1997; 226(3): 279-87.

6. Fisher B et al. Ten-year result of a randomised clinical trial comparing radical mastectomy and total mastectomy with or without radiation. N Eng J Med 1985; 3 I 2: 674-8I.

7. Benson EA, Thorogood J. The effect of surgical technique on local recurrence rates following mastectomy. Eur J Surg Oncol 1986; I2: 267-7I.

8. Carter CL, Allen C, Henson DE. Relation of tumor size, lymph node status, and survival in 24740 breast cancer cases. Cancer 1989; 63: $181-7$.

9. Xianglin D, Freeman JL, Goodwin S. The declining use of axillary dissection in patients with early breast cancer. Breast Cancer Res Treat 1999; 53(2): 137-44.

10. Recht A, Houlihan MJ. Axillary lymph nodes and breast cancer. Cancer 1995; 76(9): |49|-5|2.

I I. Chetty $U$ et al. Management of the axilla in operable breast cancer treated by breast conservation: a randomized clinical trial. Br J Surg 2000; 87: 163-9.

12. Guiliano $A E$ et al. Lymphatic mapping and sentinel lymphadenectomy for breast cancer. Ann Surg 1994; 220(3): $391-401$.

13. Fisher B, Wolmark N, Bauer M. The accuracy of clinical nodal staging and of limited axillary dissection as a determinant of histologic nodal status in carcinoma of the breast. Surg Gynecol Obstet 198I; I52: 765-72.

14. Ververs AJJM et al. Risk, severity and predictors of physical and psychological morbidity after axillary lymph node dissection for breast cancer. Eur J Cancer 2001; 37: 991-9.

15. Hack TF et al. Physical and psychological morbidity after axillary lymph node dissection for breast cancer. J Clin Oncol 1999; 17: |43-9.

16. Schrenk $P$ et al. Morbidity following sentinel lymph node biopsy vs axillary lymph node dissection for patients with breast carcinoma Cancer 2000; 88(3): 608-14.

17. Erikson VS et al. Arm oedema in breast cancer patients. J Natl Cancer Inst 200I; 93(2): 96-III.

18. Cabanas RM. An approach for the treatment of penile carcinoma. Cancer 1977; 39: 456-66.
19. Morton DL, Wen DR, Wong JH. Technical details of intraoperative lymphatic mapping for early stage melanoma. Arch Surg 1992; 127 : 392-9.

20. McMasters KM et al. Sentinel-lymph-node biopsy for breast cancer - not yet the standard of care. N Eng J Med 1998; 339: 990-5.

2I. Borgstein PJ et al. Sentinel lymph node biopsy in breast cancer: guidelines and pitfalls of lymphoscintigraphy and gamma probe detection. J Am Coll Surg 1998; 186: 275-83.

22. Dunnwald LK et al. Technical aspects of sentinel node lymphoscintigraphy for breast cancer. J Nucl Med Technol 1999; 27: 106-II.

23. Burak WEJ et al. Routine preoperative lymphoscintigraphy is not necessary prior to sentinel node biopsy for breast cancer. Am J Surg 1999; 177: 445-9.

24. De Cicco $\mathrm{C}$ et al. Lymphoscintigraphy and radioguided biopsy of the sentinel axillary node in breast cancer. J Nucl Med 1998; 39: $2080-4$.

25. De Cicco $C$ et al. Lymphoscintigraphy and feasibility of sentinel node biopsy in 83 patients with primary breast cancer. Eur J Surg Oncol 1997; 39: 495-502.

26. Krag $D$ et al. The sentinel node in breast cancer - a multicenter validation study. N Eng J Med 1998; 339(14): 94I-6.

27. Veronesi $U$ et al. Sentinel-node biopsy to avoid axillary dissection in breast cancer with clinically negative lymph nodes. Lancet 1997; 349: 1864-7.

28. Dons IPM, Stiegelis HE, Voogd AC. Kwaliteit van leven na okselklierdissectie bij patiënten met mammacarcinoom. (Quality of life after axillary dissection in patients with breast carcinoma). Ned Tijdschr v Heelkunde 1998; 7: 189-94.

29. Schijven $M$ et al. The sentinel node procedure: feasible in nonpalpable breast cancer? Eur J Nucl Med 1999; 26(4): SI, P.08.06.

30. Roumen RMH, Valkenburg JGM, GLM. Lymphoscintigraphy and feasibility of sentinel node biopsy in 83 patients with primary breast cancer. Eur J Surg Oncol 1997; 23(6): 495-502.

3I. Langenhoff BS et al. Quality of life as an outcome measure in surgical oncology. $\mathrm{Br}$ J Surg 200I; 88: 643-52.

32. Maunsell E, Brisson J, Deschênes L. Arm problems and psychological distress after surgery for breast cancer. Can J Surg 1993; 36(4): 315-20.

33. Petrek JA, Pressman PI, Smith RA. Lymphoedema: current issues in research and management. CA Cancer J Clin 2000; 50: 292-307.

34. Pain SJ, Purushotham AD. Lymphoedema following surgery for breast cancer. Br J Surg 2000; 87: I|28-4|.

35. Moffat FLJ et al. Axillary node dissection for early breast cancer: some is good, but all is better. J Surg Oncol 1992; 5 I; 8-13.

36. Liljegren G, Holmberg L. Arm morbidity after sector resection and axillary dissection with or without postoperative radiotherapy in breast cancer stage I. Results from a randomised trial. Eur J Cancer 1997; 33(2): 193-9.

37. Borup Christensen S, Lundgren E. Sequelae of axillary dissection vs axillary sampling with or without irradiation for breast cancer. A randomized trial. Acta Chir Scand 1989; I55: 5I5-20.

38. Dowlatshahi $\mathrm{K}$ et al. Lymph node micrometastases from breast carcinoma. Cancer 1997; 80(7): II88-97.

39. Bonnema J et al. Medical and psychosocial effects of early discharge after surgery for breast cancer: randomized trial. BMJ 1998; 316 : |267-7|.

Accepted for publication 20 September 2002 